\title{
Algumas questões acerca das representações do banquete na iconografia espartana do século VI a.C.
}

\author{
JOSÉ FRANCISCO DE MOURA \\ Laboratório de História Antiga da UFRJ e \\ Núcleo de Estudos Estratégicos da UNICAMP
}

\begin{abstract}
RESUMO: Este artigo tem por proposta levantar algumas questões acerca da iconografia do sympósion e do kômos presentes nos vasos lacônios de figuras negras do século VI a.C. Pretendemos efetuar uma análise do significado das imagens no intuito de entender o papel que tinham as práticas nelas representadas no seio da sociedade espartana do período. Também é nosso objetivo investigar as relações da aristocracia espartana com a aristocracia das demais póleis, verificando se o isolamento cultural da sociedade espartana, mencionado por fontes do século IV a.C., realmente ocorreu.
\end{abstract}

PALAVRAS-CHAVE: Grécia; Lacônia; vasos; iconografia; aristocracia.

O banquete privado era uma das práticas sociais gregas de cunho claramente aristocrático. Temos conhecimento de sua prática em cidades como Atenas e Corinto desde meados do século VI a.C. Além da iconografia dos vasos dessas cidades representarem-no, alguns textos produzidos no período clássico mencionam abertamente o banquete como um local de encontro de ricos cidadãos.

As informações literárias advindas do período clássico, porém, afirmavam a proibição da prática de banquetes e refeições privadas em Esparta. Segundo Xenofonte (Constituição dos Lacedemônios 5,2), a lei espartana proibia as refeições em casa, obrigando os cidadãos a participarem das refeições comuns - as famosas sissítias. Plutarco também menciona a proibição, citando o exemplo do rei Ágis, que, ao voltar de uma campanha de guerra, teria sido punido por não ter comparecido a essas refeições (Plutarco, Vida de Licurgo 12). Ainda segundo Xenofonte (República dos Lacedemônios, 10,7), a contribuição para as mesas públicas era cobrada compulsoriamente em forma de impostos, sendo a sua contribuição uma das condições necessárias para se tornar um cidadão pleno.

Outras informações sobre a sissítia estão espalhadas por quase toda a documentação literária do período clássico e posterior, motivo que tinha feito a historiografia considerá-la como uma prática comum à sociedade espartana desde os primórdios de sua história. 
Pensar que a sissítia era uma prática muito antiga, porém, equivaleria a considerar que, em Esparta, as práticas comensais teriam, durante centenas de anos, uma organização social e um sentido ritualístico bastante diferente do que era verificado em outras sociedades gregas, pois a referida prática era um fenômeno social sem precedentes nas demais póleis. Havia banquetes públicos em várias comunidades gregas, mas, pelas poucas informações que as fontes nos passam sobre esses eventos, eles estariam muito longe do caráter militarista e igualitário da prática espartana.

Logo, teria sido o banquete privado uma prática aristocrática proibida na aristocrática Esparta? Será que a aristocrática elite espartana diferenciava-se tanto assim das elites das demais póleis como nos informa a tradição literária? Será que Dionisos, um deus reverenciado nos banquetes aristocratas de outras póleis, teria sido ignorado na "apolínea" Esparta?

Para tentar responder a essas perguntas é necessário compreender o desenvolvimento histórico da sociedade espartana durante o século VI através da confrontação dos diversos tipos de fontes, tendo cuidado, contudo, de analisar e situar cada uma na especificidade de seu gênero e no contexto temporal de sua produção.

Pretendemos demonstrar, neste artigo, através do estudo da iconografia em vasos de figuras negras, que a prática do banquete não era proibida em Esparta pelo menos até 0 terceiro quartel do século VI a.C. Na verdade, muito pelo contrário, a referida prática era muito comum na vida da aristocracia local. Ela foi representada nos vasos obedecendo aos mesmos padrões canổnicos de sua realização mencionados pela documentação textual do período e de períodos posteriores.

\section{Os vasos de figuras negras e a representação do banquete}

A iconografia contida em vasos de cerâmica desvela um novo quadro da presença da prática do banquete e dos cultos e festas dionisíacas em Esparta. Ali, verificamos que, no início do século VI a.C., as imagens de banquetes estavam presentes com todas as características que a ideologia aristocrática do período tinha formatado para si própria.

Em nossa visão, o conceito de Ideologia, em que pesem todos os percalços e obstáculos heurísticos de sua historicidade, é passível de ser um instrumento cognoscível com vistas a se dar conta de como se constrói um discurso iconográfico ou textual e de como opera o mundo social. A abolição do conceito, como diz Giddens, não colabora para que expliquemos como os grupos sociais defendem representações seccionais como se fossem representações de toda sociedade, mistificando as contradições dos sistemas sociais. A dispensa do conceito de Ideologia, diz ainda Giddens, tem levado os cientistas sociais e historiadores muitas vezes a "naturalizar o presente" (Giddens, 1994, p. 197).

Em consonância com Giddens, o sociólogo John B. Thompson tem se manifestado no sentido de reelaborar o conceito. Para ele, Ideologia deve ser pensada como um sistema de crenças, valores e idéias manifestadas de múltiplas formas (imagens, textos, propagandas), que tem os seus significados orientados com vistas à manutenção de relações assimétricas (1995, p. 16). Para o sociólogo inglês, a Ideologia, por isso mesmo, refere-se à maneira pela qual as formas simbólicas - no nosso caso, as imagens - são mobilizadas para 
produzir sentidos que afirmem e corroborem as relações sociais e de dominação existentes nas sociedades.

As formas simbólicas não são propriamente falsas ou errôneas no que concerne a retratar a "realidade social", proposta essa defendida por algumas correntes do marxismo. As formas simbólicas, pelo contrário, "são constitutivos das relações sociais" (Thompson, 1995, p. 76), na medida em que estão envolvidas na função de criar as próprias relações entre as pessoas e os grupos. Elas, em geral, porém, produzem e reproduzem relações assimétricas entre essas mesmas pessoas e grupos.

Os itens que aparecem nas imagens em vasos de cerâmica são formas simbólicas às quais são conferidos sentidos e significados. As formas simbólicas não são fenômenos naturais da cultura ou isentas de significados ideológicos, porquanto estão sempre inseridas em um contexto histórico-social e politicamente estruturado.

No caso das imagens de banquetes dos vasos lacônios de figuras-negras do período, podemos afirmar que as mesmas apresentam vários itens da ideologia aristocrática, podendo ser enumerados alguns fatores bastante pontuais que a caracterizam. São exemplos a presença das sofisticadas concubinas, a representação de vestimentas estilizadas usadas pelos convivas, a pintura da Kliné enquanto símbolo de descanso dos bens nascidos, e, por fim, a afirmação do caráter sagrado e sobrenatural do encontro, manifestado nas figuras aladas que aparecem nas cenas ao lado dos principais participantes. Poderíamos adicionar ainda o tamanho e a estética dos corpos dos principais protagonistas e sua posição em relação aos demais participantes.

As cenas de simpósio e kômos, aqui chamadas genericamente de Banquete, perfazem um significativo tema presente em vários itens na iconografia espartana. Além de estarem presentes nos vasos de figuras negras, komastas e simposiastas também aparecem em estatuetas de bronze e de chumbo dedicadas aos diferentes santuários da Lacônia.

São conhecidos até agora cerca de trinta e dois vasos lacônios representando cenas relativas à prática do simpósio e do kômos. Poucos destes vasos estão preservados em sua totalidade. Uma grande parte deles constitui-se apenas de fragmentos, onde as poucas figuras que aparecem são suficientes para atestar que as cenas que ali foram pintadas tratavam da representação da referida prática.

Grande parte dos vasos lacônios de figuras negras representando práticas de simpósio ou kômos foi encontrada pelos arqueólogos em sítios fora da sua região de produção. A maioria desses vasos vem de locais como a Etrúria, Samos, Tarento e Cirene, onde, no período em que foram comercializados, as aristocracias governavam e eram aliadas de Esparta. Os vasos foram encontrados em diferentes contextos, mas, em geral, pode-se dizer que a maioria deles provém de suntuosas tumbas e imponentes santuários. Os locais de achados desses vasos já nos fazem inferir sobre o estatuto social de seus consumidores, na medida em que os mesmos devam ter sido obtidos por pessoas ricas para serem ofertados aos deuses, para serem utilizados como objetos de uso cotidiano.

Saber o preço dos vasos gregos de qualquer período é um antigo problema com que os historiadores e arqueólogos ainda se deparam. Na verdade, sabemos o preço de um nú- 
mero muito pequeno deles, quase todos do período clássico (Boardman, 1988, 27-33). Isso tem levado a algumas hipóteses diferenciadas.

Para Gill e Vickers, por exemplo, os vasos figurados seriam pouco custosos, o que implicaria que eles seriam consumidos por pessoas pobres. Os ricos, afirmam, consumiriam os vasos de ouro, prata e bronze (Gill, 1988, p. 35-43; Gill \& Vickers, 1994, p. 1-31). Gill afirma, ainda, em sua tese nada ortodoxa, que o número de sepulturas nas quais os vasos foram encontrados é muito pequeno e que esses enterramentos poderiam ser de pessoas pobres. Os ricos poderiam ter escolhido a cremação durante o século V a.C.

A hipótese geral de Gill e Vickers tem sido bastante combatida (Boardman, 1988, p. 28-9; Hoffmann, In: Goldhill \& Osborne, 1994, p. 28-51). Na verdade, ambos os autores privilegiam apenas alguns poucos dados da Atenas do século $\mathrm{V}$ a.C. para formularem suas hipóteses. Isso implica dizer que, mesmo para a Atenas daquele período, o que afirmam parece muito pouco provável. Tumbas de atenienses ricos são mencionadas o tempo todo pelas fontes dos séculos V e IV, e a cremação parece ter sido apenas uma exceção dos tempos da peste (429-7) (Morris, 1994).

O número de sepulturas descobertas pelos arqueólogos, de fato, é pequeno em relação ao total de habitantes de Atenas. Porém, isso também se dava em virtude do caráter esparso de parte da população ática do século V a.C. (Chevitarese, 2001). Somente uma pequena parte do corpo cívico era enterrada próxima da ásty, mais precisamente no Cerâmico. Muitos corpos eram enterrados no próprio dêmos onde os cidadãos e seus escravos habitavam. Outras regiões em que os corpos eram enterrados de forma mais concentrada, como a própria Esparta e comunidades menores do Peloponeso, não foram mencionadas pelos referidos autores.

No que concerne ao preço dos vasos, a idéia de considerá-los baratos não tem sentido, na medida em que não se estipula uma referência para se estabelecer uma relação. Os vasos figurados seriam baratos, mas em relação a quê?

O Quadro 1, por exemplo, nos fornece os preços de alguns vasos que nos chegaram através de uns poucos documentos áticos do século V. Observa-se nele que os preços variavam principalmente em função do tamanho e dos tipos dos vasos. Os vasos de segunda mão e os não figurados, chamados de lisos pelos arqueólogos, parece que eram os que tinham os menores preços, ao passo que os vasos maiores e figurados podiam chegar a 18 óbolos. 


\section{Quadro 1}

\section{Relação de preços dos vasos áticos no Século $\mathbf{V}^{1}$}

\begin{tabular}{|l|c|c|c|}
\hline \multicolumn{1}{|c|}{ Tipos de Vasos } & Tamanho & Período & Preço (em óbolos) \\
\hline $\begin{array}{l}\text { Hidria ática de figuras } \\
\text { vermelha }\end{array}$ & $47 \mathrm{~cm}$ & Meados do século V & 18 óbolos \\
\hline $\begin{array}{l}\text { Hídria ática de figuras } \\
\text { vermelhas }\end{array}$ & $41 \mathrm{~cm}$ & Meados do Século V & 12 óbolos \\
\hline $\begin{array}{l}\text { Cratera ática de figuras } \\
\text { vermelhas }\end{array}$ & $42 \mathrm{~cm}$ & Meados do Século V & 11,5 óbolos \\
\hline $\begin{array}{l}\text { Lékitos ático de figuras } \\
\text { negras }\end{array}$ & $40 \mathrm{~cm}$ & Inicio do século V & 6 óbolos \\
\hline $\begin{array}{l}\text { Cratera de sino ática } \\
\text { de figuras vermelhas }\end{array}$ & - & Final do século V & 4 óbolos \\
\hline $\begin{array}{l}\text { Ánfora Panatenaica } \\
\text { ática de figuras negras } \\
\text { (de Segunda mão) }\end{array}$ & - & Inicio do século V & 3 óbolos \\
\hline $\begin{array}{l}\text { Anfora pescoço ática } \\
\text { de figuras vermelhas } \\
\text { (de Segunda mão) }\end{array}$ & - & Meados do século V & 3 óbolos \\
\hline $\begin{array}{l}\text { Cratera de Sino ática } \\
\text { lisa }\end{array}$ & - & Meados do século V & $\begin{array}{l}\text { Cerca de } 8 \\
\text { óbolos (1,5 } \\
\text { dracmas) }\end{array}$ \\
\hline $\begin{array}{l}\text { Taça ática lisa } \\
\text { (cáa átculo aprox.) }\end{array}$ & - & Meados do século V & 0,5 óbolo \\
\hline
\end{tabular}

Obviamente, é muito difícil utilizar tais dados exibidos acima para generalizar os preços dos vasos para um período anterior, produzidos em uma outra região, principalmente se levarmos em conta as particularidades da economia grega. A economia monetária só foi plenamente estabelecida em meados do século IV a.C. (Reden, 1996). A introdução da moeda, embora tendo-se dado dois séculos antes, não foi disseminada de forma igualitária e consistente em todo o mundo grego ${ }^{2}$. Muitas regiões, ainda nos séculos V e IV, não a utilizavam de forma sistemática. Era o caso da região do Peloponeso, por exemplo, onde Esparta havia estabelecido sua hegemonia política e militar.

Devido a isso, os vasos figurados do século VI não podem ter sido transacionados em espécie de forma sistemática e regular. Os vasos figurados áticos e coríntios foram os primeiros a serem comercializados com frequêencia, ainda durante o século VII. Porém, podese considerar que muito dificilmente a compra de grande número dos mesmos fosse feita com moedas. A hipótese mais viável é que grande parte deles tenha sido trocada por outros produtos ou mesmo por ouro e prata em espécie. No caso de Esparta, essa possibilidade é

1 Os preços aqui apresentados são, em sua maioria, oriundos de uma estela ática de meados do século V a.C., mencionadas por Boardman (1988, p. 31).

2 Uma das melhores sistematizações sobre a cunhagem e o uso das moedas em solo grego no periodo Clássico é a obra de Martin (1985). 
ainda maior devido ao caráter rudimentar de sua economia. Temos informações sobre uma transação do final do século VII, por exemplo, na qual a compra de uma casa teria sido feita através de produtos, ouro e prata não cunhada ${ }^{3}$. Aliadas a isso, as escavações e prospecções arqueológicas realizadas pela equipe inglesa na região confirmam a ausência de moedas para período anterior a 360 (Catling et alli, 1996, p. 196).

Isso não quer dizer que o seu preço teria sido acessível a todos. O quadro 1 serve para compreendermos que havia uma relação de preços diretamente proporcional ao tamanho e à decoração do vaso. Os vasos figurados maiores (hídrias, por exemplo) seriam mais caros que os figurados menores (taças) e muito mais caros que os vasos menores lisos (taças).

Afora isso, segundo Boardman, o preço pago por um dia de trabalho na Atenas no fim do século $\mathrm{V}$ girava em torno de 6 óbolos (1 dracma), o que era um valor extremamente baixo para a sobrevivência de um homem solteiro, quiçá casado e com fillhos. Logo, o preço de uma hídria figurada de grande tamanho $(47 \mathrm{~cm})$ poderia custar até três dias de trabalho de um pobre "assalariado" ateniense. Considerá-la, mesmo na Atenas do século V, como um item de consumo comum aos pobres é, em nossa visão, um grande erro.

Para o caso específico do período arcaico, essa hipótese é ainda mais absurda. Várias ocorrências representadas nos vasos são as mesmas mencionadas pelos poetas, comuns ao universo das práticas sociais dos aristocratas do final do século VII e do século VI. Muitos poetas eram testemunhas oculares dos banquetes em que os aristocratas estavam envolvidos. Os poetas muitas vezes narraram suas práticas sociais, sua estética e seus valores.

Aliadas a tudo isso, as escavações arqueológicas parecem confirmar que a população mais pobre não tinha acesso a tais vasos, já que a concentração dos mesmos sugere que somente uma parte significativamente pequena da população os consumia. Na Hélade propriamente dita, como em outras regiões colonizadas pelos helenos, os vasos figurados, em geral, têm sido encontrados em tumbas, santuários e em casas. Nas pequenas fazendas, eles praticamente inexistiam ${ }^{4}$. Nos santuários, eles aparecem ao lado de vasos simples e, por vezes, grosseiros, sem nenhuma representação pictórica em suas superfícies.

Nas tumbas, ocorre a mesma discrepância. Essa desigualdade nos padrões das dedicações religiosas e funerais já indica, a nosso ver, a diferenciação social dos dedicantes.

Sendo assim, os vasos figurados constituem-se, no século VI, em um item da cultura material grega de uso restrito, destinado aos diversos tipos de consumo prático e simbólico implementados pela elite aristocrática das póleis e do mundo para além delas. As imagens neles retratadas eram produzidas para atender às demandas e gostos desses consumidores e não da totalidade da população grega.

Um fator de caráter político também é fundamental na confirmação do caráter aristocrático de seu uso. Nota-se que os vasos chegavam aos principais mercados quando essas

3 Trata-se da casa do Rei Polidoros, que teria sido adquirida após a sua morte, e cujo pagamento foi feito em ouro e prata não cunhada, e bois (Pausânias, III 32 ).

4 Essas são pelo menos as constatações das equipes de prospecções em Argos, Beócia e Lacônia. Para a região da Argólida, ver Jameson, H. et alii (1994). Para as da Beócia ver, entre outros, Gaffney \& Gaffney (1986, p. 65-70); e para as da Lacônia ver Catling et alii (1996 n. 12). A única exceção parece ser a região de Vari na Ática. Ver Jones (1973, p. 355-452). 
comunidades eram governadas por grupos aristocráticos ligados por aliança diplomática, e possivelmente militar, com os espartanos. Quando os governos desses locais foram alterados, os vasos tiveram a sua exportação imediatamente interrompida. São exemplos bem documentados os casos de Samos e de Sardis. Quando as aristocracias locais foram derrubadas por Polícrates e pelos persas, respectivamente, verificou-se, imediatamente, um corte no envio de vasos para aquelas regiões. $O$ mesmo fenômeno parece ter ocorrido em relação a Cirene e à Etrúria.

Isso demonstra que os espartanos, mesmo não estando envolvidos na produção mecânica dos vasos, determinavam sua circulação e consumo, imprimindo ao comércio de vasos figurados a condição de dependência em relação à sua política externa com regimes ou famílias aristocráticas.

A disseminação do tema do banquete entre os pintores é prova da extensão e importância da referida prática. Nos vasos lacônios de figuras negras, as cenas contendo a referida temática foram pintadas por todos os grandes pintores lacônios, sendo comercializadas para dentro e, principalmente, para fora de Esparta, durante grande parte do século VI a.C. A forte incidência de vasos com essa temática nos leva a considerar que a referida prática era bastante comum na primeira metade do sexto século antes da nossa era ${ }^{5}$, e no começo da primeira década que se seguiu, fazendo parte do cotidiano da elite local.

Algumas características dos temas pintados permitem aos estudiosos observarem alguns aspectos bem marcantes. Para Boardman (1988, p. 97), por exemplo, o fato de nenhum detalhe da vida cotidiana de mulheres, crianças e escravos aparecerem nos vasos com essas pinturas é sinal suficiente de que se tratava de uma prática eminentemente masculina e que a preocupação dos pintores era representar o mundo fechado dos aristocratas.

Para Smith (1998, p. 75), por sua vez, uma forma de compreender o teor das cenas de banquete nos vasos lacônios seria comparando-os numericamente com os de Corinto. Se o número total de vasos lacônios figurados é muitas vezes inferior ao total dos vasos figurados coríntios conhecidos, proporcionalmente, porém, o número de cenas de banquete nos primeiros é surpreendente mais alto. Smith contabilizou 32 vasos lacônios, com aquelas cenas, contra 40 dos similares coríntios, o que indicaria, para o autor, que a referida prática era considerada de maior importância na sociedade espartana.

Já na visão de Faustoferri (1986, p. 120), todos os vasos lacônios se agrupariam em duas tipologias básicas: os vasos de tipo erótico e aqueles de teor heróico. Cenas referentes a todos tipos de práticas sociais seriam norteadas por aqueles dois aspectos. Para ela, a temática do simpósio e do komos nas cenas dos vasos lacônios apontaria para o fato de que na "sociedade lacônia, o sentido erótico do banquete era vagamente oriental".

O simpósio, na concepção de Hoffmann (1994, p. 32), representava uma prática social na qual os ideais de luxúria e de diferenciação dos participantes eram realizados e alcançados. Os aristocratas gregos teriam feito dele seu ponto de encontro habitual, local onde assuntos e valores de grupo se reforçavam e atualizavam.

s Todas as datações referem-se ao período anterior a Cristo. 
Em consonância com ele, Buxton (1994, p. 28) considera que, nesses encontros, a solidariedade e o sentimento de identidade dos aristocratas, ou aquilo que Alex Callinicos (1987) chama de Coletividade, se fortaleceria. O encontro serviria, nessa hipótese, para norteamento da ideologia aristocrática.

Dois outros fatores indicam que as referidas cenas eram pintadas a partir da vida social: a ocorrência, como já mencionamos, do tema em outros itens da iconografia (estatuetas de bronze e chumbo) e o refinamento dos detalhes presentes nas cenas pintadas com aquela prática. Esta última característica demonstra, a nosso ver, que o pintor lacônio estava em constante e estreito contato com o ambiente em que se realizava o banquete, podendo ser testemunha ocular de tais encontros.

A incidência de vasos com essa temática nos diz mais. $\mathrm{O}$ alto número de cenas de banquetes nos vasos, bastante superior ao número de cenas de guerra, implica que a imagem de uma Esparta militarista e austera, criada no período clássico, não tinha relação com a Esparta desse período. Como afirma Powell (1998, p. 36), "os vasos lacônios parecem apresentar um quadro de uma sociedade auto-indulgente que o período clássico não permitiu".

A presença da prática do banquete nos vasos indica que o mesmo, até cerca de 530, ainda não havia sido proibido ou substituído pela sissítia, que foi, posteriormente, a principal, e talvez única, prática comensal coletiva permitida em Esparta. O simpósio e o kômos eram práticas sociais comuns a grupos restritos de pessoas também em outras póleis, o que aproximava a aristocracia das mesmas com a elite aristocrática espartana no tocante a essas reuniões de caráter privado. Normalmente, também nas outras póleis, essas eram ocasiões onde ricos amigos se reuniam para falar de política, beberem, comerem e divertirem-se com jovens rapazes, prostitutas e músicos.

Em relação às fontes literárias, as informações que temos sobre a organização e a função do simpósio e do kômos são oriundas de vários autores de diferentes períodos. No período arcaico, as fontes principais são os poetas, dentre os quais se destacam Alcman, Alceu, Arquílocos, Anacreonte, Teógnis e Baquílides.

Posteriormente, no período clássico, informações isoladas e contingenciais aparecem em outros vários tipos de fontes, desde historiadores e filósofos, até comediógrafos.

No período romano, Ateneu elaborou uma imensa obra na qual um sem-número de autores anteriores, cujos trabalhos não nos chegaram, são citados mencionando detalhes do banquete.

Graças a essa riqueza documental, o banquete revela-se como uma das práticas sociais gregas mais bem conhecidas. A compreensão de seu funcionamento nos vários períodos colabora para que tenhamos algum controle sobre os detalhes das cenas que o retratam, permitindo a identificação de vários itens do encontro.

Nas cenas de simpósio e kômos da Lacônia, a presença da kliné, móvel no qual os comensais se reclinavam, era uma constante. Ela aparece pintada na grande maioria das imagens. Muitas vezes, o pintor também retratava detalhes menores que envolviam o comensal na kliné, como a almofada na qual se apoiava ou os tecidos que o envolviam.

Uma outra característica contida nas cenas revela o conhecimento que os pintores tinham acerca da prática. Os vasos utilizados no encontro, em geral lakainas, taças, crate- 
ras, olpes e cântaros, aparecem representados fielmente no tocante às suas formas e estilos de fabricação. Nota-se, por isso mesmo, que o pintor tinha total consciência sobre o que os comensais faziam com os vasos durante aquele encontro, sobre os tipos de vasos que eram usados em cada ocasião, e até sobre os detalhes das formas dos mesmos em cada período de seus usos. Os pintores representavam os comensais segurando as taças ou lakainas para ingerir as bebidas, usando crateras em locais mais afastados como recipientes de mistura do vinho com água, e utilizando as olpes para retirá-los das crateras.

Essas características mostram a preocupação dos pintores em retratar fielmente alguns itens materiais utilizados nos encontros e que se constituíam em elementos básicos da realização do mesmo. A representação exata dos vasos e móveis presentes nos encontros nos levam a inferir que os pintores se esforçavam para dar às pinturas um caráter real da reprodução desses encontros dos membros da elite espartano. Essa reprodução de cunho "fotográfico" era, obviamente, idealizada, com as formas simbólicas sendo mobilizadas para atender aos anseios e demandas dos espartanos.

Em algumas pinturas, aparece claramente, também, a preocupação do pintor em mostrar detalhes das comidas ingeridas. Uma dessas comidas, por exemplo, aparece com certeza em duas cenas, e provavelmente em uma terceira. Trata-se de espécies de bolinhos redondos, provavelmente feitos de cevada. Eles eram chamados kámmata, e muitas vezes eram servidos com azeite (Nicocles, In: Ateneu, IV, 141a).

A presença de músicos nos encontros é atestada em 9 vasos. Eles podiam ser representados tocando o aulós e a cítara. Muitos músicos estavam vestidos com trajes orientais, indicando que não eram espartanos. Não consideramos válida a interpretação de Pipili (1987, p. 50) de que alguns desses músicos poderiam ser o deus Apolo. Na verdade, a presença de músicos nos banquetes é atestada em quase todas as fontes sobre os mesmos, sendo sua função divertir os convivas.

Há pelo menos uma cena em que uma mulher luxuosamente vestida aparece tocando um aulós, o que poderia caracterizá-la, certamente, como hetaira. Ocorre que Alcman mencionou que espartanas também usavam vestidos como aqueles (PMG 1). Ainda assim, fica a pergunta: o que uma matrona "bem nascida", que era preparada para o casamento e a vida doméstica, estaria fazendo em uma prática eminentemente masculina?

As mulheres, por sinal, podem estar representadas em muitas cenas, mas, com certeza, a sua presença só pode ser atestada em um ou outro vaso. A incidência de vestidos e cabelos longos em muitos personagens pintados dificulta uma correta identificação, tendo em vista que nem sempre os pintores pintavam as mulheres com a cor branca, como era comum em alguns vasos de outras localidades.

O sexo explícito feito entre homens aparece pintado, com certeza, em duas cenas e, talvez, em uma terceira. O coito anal é fortemente indicado pela posição do corpo, confirmando a prática de relações homossexuais em tais encontros (Fig. 1). A incidência de galos em outros três vasos confirma a atmosfera amorosa e sedutora do encontro. 


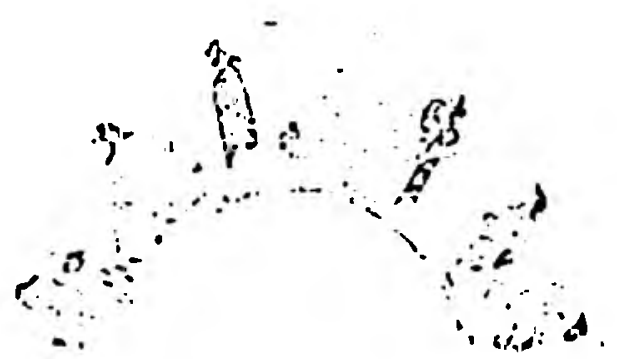

Fig. 1 - Reconstifuiço pur Pipili. 1987, lig. 95.

Algumas cenas representando o kômos indicam que essa procissão festiva que se seguia ao banquete saía pelas ruas, como em outras póleis. Os pintores Typhon e Rider quiseram caracterizar as procissões festivas fora do ambiente privado pintando construções . (templos?) que supostamente ficariam em espaço público.

O kômos aparece em um grande número de vasos, somando 20 das 28 cenas que conhecemos com a prática do banquete. Muitas cenas, porém, misturam os dois tempos festivos, incluindo também o simpósio. Dançarinos nus e vestidos aparecem em quase todas as cenas, indicando $o$ ambiente festivo do encontro. Eles podiam representar os comen- 1 sais após o efeito do vinho ingerido, já que muitas vezes aparecem próximos a crateras ou : segurando taças.

Os vasos figurados com esta temática podiam ser usados de várias formas. Eles poderiam pertencer ao aristocrata como seu objeto de uso cotidiano, poderiam ser posteriormente ofertados aos santuários como objeto de dedicação sua aos deuses, ou ainda ser enterrados com ele após a sua morte. Em virtude desse aspecto fortemente pessoal de sua' relação com o vaso, não se deve descartar a hipótese de muitas cenas representarem encontros específicos de pessoas específicas, e de que os vasos serviriam, dentro de Esparta, para atender a encomendas privadas. Os vasos exportados de Esparta podem, por isso mesmo, representar encontros reais ocorridos nas casas dos espartanos.

\section{A padronização iconográfica de um encontro comensal privado}

As similaridades existentes entre vasos pintados por diferentes pintores no tocante às cenas de banquete podem advir da regularidade da organização daqueles, ocorrida em diferentes encontros frequientados pelos pintores.

Algumas cenas de banquetes mostram que, em geral, os principais convivas eram pintados a partir de um tipo físico esteticamente padronizado. Alguns homens que geralmente aparecem na posição central da cena em tamanho maior ou em destaque com relação a outras pessoas, quase sempre possuem cabelos longos arranjados em cachos artificiais,' com barba longa, sem bigodes e com porte físico robusto. Isso indica que os homens ali presentes seriam adultos, de boa condição econốmica e que exercitariam seus corpos com freqüência, condições que a maioria dos espartanos possuía. 
A representação histórica esses homens coincide com as características físicas que as fontes escritas mencionavam acerca da estética dos espartanos. Esses, quando adultos, se caracterizavam por usarem cabelos muito longos e cacheados (Heródoto, I, 82; VII, 208; Xenofonte, A Constituição dos Lacedemônios 11,3; Plutarco, Lisandro I,1; Licurgo XXII,1), barba longa (Plutarco, Fócion X; Lisandro, I,1) e ausência completa de bigodes (Aristóteles In: Plutarco, Vida de Cleomenes, IX, 2; Antífanes In: Ateneu, IV, 143c). Parece que o uso dessa aparência era vedada aos segmentos sociais inferiores. Uma estela funerária de um perieco representava-o com os cabelos curtos e ondulados, sem barba e muito magro. Nos vasos, pessoas que aparecem servindo aos comensais nos banquetes são representados em tamanho menor, de cabelos diferentes e geralmente ou muito magros ou muito gordos.

Em nossa visão, esses homens representados podiam ser os mesmos cidadãos que eventualmente compravam as taças com a pintura de seus próprios encontros comensais. Estrangeiros visitando amigos espartanos podia leva-la como recordação, como bens de prestígio que os distinguiam.

Uma cena específica do corpus lacônio pode servir de padrão para entendermos a representação da realização do banquete em Esparta. O vaso, restaurado pelos especialistas, pinta a cena em uma grande riqueza de detalhes. Por isso, ele pode ser considerado o equivalente do vaso François para o banquete espartano na medida em que reúne quase todos os ícones daquela prática, presentes em outras cenas de forma mais isoladas.

O exemplar é uma taça do Naukratis Painter, de c. 565, habitual produtor para o mercado interno e pintor que gostava de representar o banquete em toda a sua ocorrência. $O$ vaso foi exportado para a Etrúria, e lá serviu de oferenda votiva em um santuário próximo ao porto de Lavínium (Fig. 2).

No vaso, observam-se dois comensais barbados no centro da cena, em tamanhos descomunais, se comparados com as outras pessoas pintadas. Eles possuem barbas e cabelos longos, vestem himátion, e olham-se com tom de cumplicidade mútua. Eles seguram as taças em suas mãos direitas. A simetria de suas posturas confirma a tentativa do pintor de homogeneizá-los, diferenciando-os dos demais.

No alto, por trás de suas cabeças, três seres humanos alados, de porte menor, dirigemse a eles com as mãos espalmadas, como a garantir-lhes a aquiescência do sobrenatural. No chão, em pé, quatro pessoas de porte menor aparecem à esquerda e à direita da kliné. Uma delas, à direita, toca um aulós. Outra, no lado oposto, está quase desaparecida. Dois homens menores aparecem um de cada lado, portando chapéus em forma de florais estilizados.

Uma mesa, com fruteiras cheias de bolinhos, aparece na frente da kliné. Cães, cobras e aves estão junto a ela, aos pares, em posições opostas, mas eqüidistantes.

No nível inferior, a cena mostra um outro instante do banquete, no qual pessoas nuas embriagadas encontram-se próximas a uma cratera e a pequenas olpes. Dois homens à direita parecem estar dançando. Um outro à frente parece embriagar-se e um quarto, mais adiante, vomita. No canto direito, dois homens aparecem muito próximos, um sem barba e outro barbado, de falo ereto.

O pintor desta cena, em nossa concepção, quis retratar o banquete ocorrido na casa de eminentes espartanos, que são representados em tamanho maior. Eles se diferenciam dos demais 
participantes, de diversas formas: roupas, tamanho, posição na kliné e proximidade dos seres alados. Quanto a estes últimos, pode-se tratar de Erotes, ou mesmo, como afirma Pipili (1987, p. 64-70), de seres alados da natureza.

As pessoas em tamanho menor não são espartanos, mas escravos, estrangeiros ou periecos, que ali estão para trazer prazer aos dois espartanos, tocando a flauta ou servindo-os em outros favores. Pessoas de tamanho menor que os comensais aparecem em mais dois vasos, assinalando hierarquia social.

Os cães, ambos com coleiras, assinalam a presença do ambiente caseiro. Os animais pertenceriam a um ou aos dois espartanos, já que Estesícoro mencionou que cães ficavam próximos às mesas dos banquetes ( $\mathrm{PMG} \mathrm{338).} \mathrm{O}$ cão era um animal bastante comum ao universo espartano da caça. Cães de raça lacônios eram famosos desde o período arcaico, quando Polícrates importou uma série deles. No Século V, Xenofonte escreveu um tratado de caça com cães, provavelmente baseado em suas experiências com os animais lacônios, já que seu amigo, o rei Agesilau, era criador daqueles animais (Xenofonte, Agesilau 9.6).

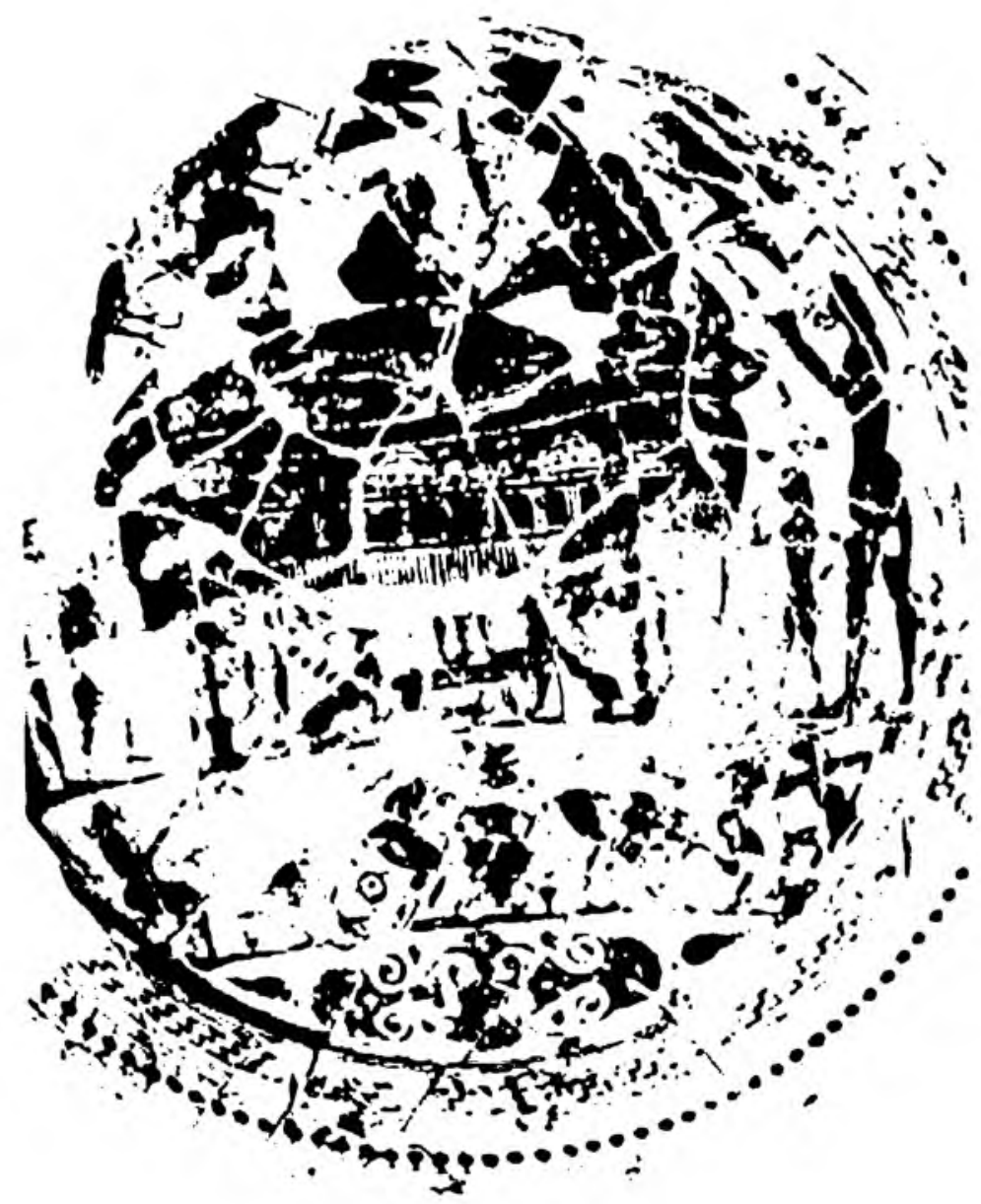

Fig. 2 - Foto tirada pelo autor, reproduzida de Faustoferri, 1986, fig. 435. 
No kômos, em um outro momento da festividade, o pintor tenta retratar como o encontro afetava alguns participantes. Eles aparecem envolvidos em danças e bebedeiras excessivas. A cópula homossexual se encaminha entre dois dos participantes.

Em nossa visão, o significado geral da cena valoriza a posição social dos espartanos, reforçando sua superioridade frente a outros atores sociais. Esse processo se daria de várias formas: na representação dos espartanos em tamanho maior e na aproximação dos mesmos com o mundo mítico. A cena também valoriza a prática aristocrática do banquete, enfatizando alguns detalhes mínimos do encontro.

Ao migrar para outras regiões, os vasos poderiam ser compreendidos de diversas maneiras. Em ex-colônias de Esparta, como Cirene, Tarento e Tera, a cena seria facilmente identificada como pertencendo aos encontros comensais dos "parentes" espartanos. Ela poderia ser ofertada aos deuses como um presente, ou acompanhar o morto como seu objeto pessoal.

Em Samos, a cena também seria facilmente compreendida, na medida em que a aristocracia local tinha fortes laços de aliança com a aristocracia espartana. Os sâmios ajudaram os espartanos na segunda Guerra da Messênia. Sabemos, também, que um arquiteto sâmio estava trabalhando em Esparta em c. 570, o que o faria ter um contato mais estreito com as práticas sociais dos espartanos. ${ }^{6}$ Muitos vasos de diferentes temáticas eram oferecidos no templo de Hera, independente se o teor das cenas se relacionasse com os atributos da esposa de Zeus.

$\mathrm{Na}$ Etrúria, onde a prática do banquete funeral também existia, imagina-se, a priori, que a cena poderia ser mais difícil de ser compreendida. Os etruscos, ao que sabemos, jantavam em casa com as suas esposas e não praticavam o homossexualismo (Spivey, 1997, p. 133). O imenso número de vasos gregos encontrados em seu território, contudo, é prova de que os contatos culturais entre etruscos e gregos, sobretudo espartanos, eram muito mais estreitos que o quase total silêncio das fontes nos leva a supor. É muito provável que alguns etruscos mais ricos freqüentassem Esparta (e vice-versa). Lá, eles tomariam contato com tais encontros comensais, apreendendo ou compartilhando o significado dos mesmos quando se apossavam deles.

Nessa hipótese, os vasos teriam a função de bens de prestígio, na medida em que poderiam ser considerados como símbolos de status e prova material da influência política dos seus possuidores junto a um aliado de peso no mundo grego. $\mathrm{O}$ fato deste vaso e de inúmeros outros terem sido dedicados em locais sem que as imagens pintadas nos mesmos tivessem alguma relação imediata com o deus do santuário confirma essa outra função que 0 vaso podia adquirir.

A historiografia tem desprezado a hipótese de contatos interculturais mais intensos entre etruscos e gregos. Plutarco (Questōes Gregas, 296,21B) mencionou uma interessante história na qual alguns etruscos, chegando a Esparta após terem fugido de Atenas, casaramse com mulheres espartanas, tendo tido filhos dessas uniões. Eles teriam se desentendido com os espartanos por algum motivo não mencionado e partido posteriormente para Creta, onde fundaram Lyktos (Plutarco, Questões Gregas, 296.21B; Estrabão, IV, 7, 9; VI, 5, 3). Não se sabe a data de tal fato, mas a hipótese deste contato íntimo ter ocorrido no período 
arcaico é bem provável, já que nesse período era comum ver espartanos recebendo estrangeiros para morar em seu território.

Há uma outra hipótese, também provável, de que os etruscos dessem outros significados às cenas, adaptando-as à sua cultura e às suas práticas sociais. Eles poderiam ignorar que as mulheres presentes nas cenas fossem prostitutas e confundi-las com esposas. Da mesma forma, a dificuldade em se reconhecer imediatamente o sexo de algumas figuras praticando o coito, ou na eminência de praticá-lo, poderia fazê-los pensar que se tratasse de cenas envolvendo casais, o que, então, poderia ser associado a algumas festas etruscas.

A produção de cenas desse teor iconográfico demonstra, a nosso ver, que a prática do banquete em Esparta tinha características bastante similares com as mesmas práticas realizadas em outros locais e que Esparta não era, no período, a comunidade austera igualitária $\mathrm{e}$ isolada culturalmente do restante do mundo grego e fora dele.

\section{Conclusão}

Os vasos lacônios figurados são evidências fortíssimas de que, em meados do século VI a.C., a elite aristocrática de Esparta pouco se diferenciava das elites aristocráticas de outras póleis gregas. A proibição da prática do banquete e de refeições privadas em Esparta, se chegou realmente a existir como afirma a documentação literária do século IV a.C., é uma medida tomada posteriormente ao período de produção dos referidos vasos.

As cenas representadas nos vasos afirmam o status e a diferenciação social dos espartanos com relação aos demais estratos sociais, e euforizam as práticas sociais e a estética das elites. Uma das formas de mobilizar o significado das imagens para fins ideológicos era atribuindo-lhes caráter sagrado, que se revelava na proximidade de seres sobrenaturais. Logo, o significado religioso atribuído às formas simbólicas representadas na imagética desses vasos serve de pressuposto básico para manipulação do sentido dessas mesmas formas simbólicas no intuito de afirmar as práticas sociais das elites enquanto condutoras da vida política e social espartana.

Dessa forma, podemos afirmar que, pelo menos até metade do sexto século, as imagens de vasos lacônios são suficientemente claras para demonstrar que a aristocracia espartana imputava às suas reuniões comensais privadas o mesmo sentido que eram produzidos pelas aristocracias de outras póleis do período. Esparta não se configuraria, até então, como uma sociedade isolada culturalmente.

\section{Referências Bibliográficas}

BOARDMAN, John. Trade in Greek decorated pottery. In: Oxford Journal of Archaeology Vol. 7, 1988, p. 27-33.

BUXTON, Richard. Imaginary Greece. The context of Mithology. Cambridge: Cambridge University Press, 1994. 
CALLINICOS, Alex. Making History. London: Basil Blackwell, 1987

CATLING, R. et al. Continuity and Change in a Greek Rural Landscape. The Laconia Survey. Vol. II. London: British School at Athens, 1996.

FAUSTOFERRI, A. Tentativo d'interpretazione des soggeti raffigurati all'interno della laconische del seculo VI a.C. In: Studi Sulla Ceramica Laconica. Perugia: Giorgio Bretschneider, 1986, p. 119-47.

HOFFMANN, Hebert. Dulce est pro patria mori: the imagery of heroic imortality on Athenian painted vases In: GOLDHILL, Simon; OSBORNE, Robin. Art and text in ancient Greece. Cambridge: Cambridge University Press, 1994, p. 28-51.

GAFFNEY, C.F.; GAFFNEY, V.L. From Boeiotia to Berkshire: an integrated approach to geophysics and rural field survey. In: Prospezioni Arqueologiche, Vol. 10, 1986, p. 65-70.

GIDDENS, Anthony. Central Problems in Social Theory. Berkeley: University of California Press, 1994.

JAMESON, M. et al. A Greek Coutryside. The Southern Argolid from Prehistory to Present day. Stanford University Press: 1994.

JONES, J.E. et alli. An Attic Coutry House bellow the Cave of Pan in Vari. In: Annual of the British Scool at Athens, Vol. 68, 1973, p. 355-452.

PIPILI, Maria. Laconian Iconography in Sixth Century. Oxford University Press: 1987.

POWELL, Anton. Sixth-century Laconian vase painting. In: FISHER, N.; VAN ESS, Hans. Archaic Greece. New aproaches and new evidences.London: Duckworth, 1998, p. 11947.

REDEN, Sitta Von. Exchange in Ancient Greece. London: Duckworth, 1996.

SMITH, Tyler Fo. Dances, drinks and dedications: the Archaic Kòmos in Sparta. In: Sparta in Lacônia. London: British School at Athens, 1998, p. 75-81.

MOURA, José Francisco de. Some questions about symposium representations in Spartan iconography of the VI Century BC. Classica, São Paulo, 15/16, p. 63-77, 2002/2003.

ABSTRACT: To bring some questions about the iconography of the symposion and of the komos in the black figures on Laconian vases of the VI Century BC is the purpose of this article. We intend to analyse the meaning of the referred images in order to understand the importance of the represented practices to the Spartan society of that period. We also intend to investigate the relationship between the Spartan aristocracy and the aristocracy of other poleis to check if the cultural isolation of the Spartan society, mentioned by sources of the IV Century BC, really happened.

KEYS-WORDS: Greece; Lacónia; vases; iconography; aristocracy. 